\title{
PRODUÇÃO DE BIOETANOL A PARTIR DO MILHO: ESTUDO DE PROSPECÇÃO TECNOLÓGICA A PARTIR DE BASES DE PATENTES
}

\author{
Área Temática 9: Propriedade Intelectual \\ Classificação JEL: O33
}

Fabrício José Piacente, Vanessa de Cillos Silva, Dennys Eduardo Biaggi

Resumo - O artigo traça o cenário atual da tecnologia de produção de etanol de milho a partir da análise de bases de dados de documentos de patentes sobre esse tema depositado nos principais escritórios de proteção industrial. Para isso utilizou-se a ferramenta Questel Orbit de busca e análise de documentos de patentes a partir de palavras-chaves, de acordo com as etapas de busca. Para os processos e métodos de forma geral foram encontrados 1.246 documentos de interesse, sendo 10 depositados no Brasil, como país prioritário. A etapa de fermentação de $2^{\mathrm{a}}$ geração é relativamente recente e apresentou apenas 46 documentos de patentes depositados, com maior representatividade a partir de 2006.

Palavras-chave: milho, bioetanol, patentes, prospecção tecnológica

\section{Bioethanol production from corn: study prospecting technology from patent bases}

Abstract - The paper traces the current scenario of the second-generation ethanol from sugarcane production technology based on the analysis of patent documents databases on the subject deposited in major industrial protection offices. For this we used the Questel-Orbit tool for searching and analyzing patent documents from keywords: corn and fuel or biofuel or bioethanol or etanol or bioconver. Found 1,246 documents of interest, of which 10 deposited in Brazil as a priority country. The 2nd generation fermentation step is relatively new and had only 46 patents filed documents with greater representation from 2006.

Keywords: corn, bioethanol, patents, technology prospecting.

\section{Introdução}

Nos últimos anos, a bioenergia vem recebendo atenção crescente em muitos países, nos campos político, econômico e técnico-científico, especialmente em razão das preocupações com as mudanças climáticas e a segurança energética.

Verifica-se a utilização de diversos tipos de materiais para a geração da bioenergia, na maioria dos casos trata-se de matérias-primas derivadas de plantas, tais como raízes, grãos, caules ou folhas das mais variadas espécies. A nomenclatura internacional classifica todo e qualquer tipo de etanol produzido a partir de fontes originadas da biomassa de bioetanol, justamente para distingui-los do etanol produzido a partir de derivados de origem fóssil.

Nota-se que a produção mundial de bioetanol não se restringe a utilização apenas da cana-de-açúcar como matéria-prima básica, mas que outras fontes de biomassa são aproveitadas em diversos países. Dentre elas podem-se destacar os resíduos florestais, a beterraba açucareira, o sorgo, o trigo, a mandioca e o milho. 
Assim, países com pouca ou nenhuma tradição na produção canavieira tem apresentado um papel importante no desenvolvimento tecnológico de processos que utilizem novas fontes de biomassa na produção de etanol.

Segundo Souza et al. (2013), as características da biomassa ideal para a produção de bioetanol incluem: alta produtividade agrícola, curtos ciclos produtivos, baixo consumo energético, baixo custo de produção, baixos níveis de contaminantes e baixa demanda por nutrientes. Destaca-se, ainda, a importância de apresentar um balanço de carbono favorável quando mensurado por avaliações de ciclo de vida, considerando toda a cadeia de produção e o uso dos biocombustíveis.

Atualmente os EUA é maior produtor mundial de bioetanol produzido a partir do processamento do milho. Na safra de 2013/14 foram produzidos o equivalente a 51,4 milhões de metros cúbicos, mais que o dobro da produção brasileira que foi de 23,7 milhões, produzidos a partir do processamento da cana-de-açúcar. Na safra de 2013/14 foi produzido nos EUA o equivalente a 361 milhões de toneladas de milho, desse montante, 131,4 milhões de toneladas foram empregados na fabricação de biocombustível, o equivalente a mais de 36\% de todo o milho (USDA, 2015).

O salto na produção desse biocombustível nos EUA é resultado de um conjunto de fatores que inclui desde os tradicionais subsídios oferecidos pelo governo federal dos EUA até os avanços tecnológicos ocorridos na atividade. Segundo Pereira (2015), o aspecto a ser destacado no contexto é a forte participação do governo federal na definição de diretrizes e metas relacionadas à produção e consumo de biocombustíveis nos EUA, em especial do bioetanol de primeira geração (proveniente de milho).

A evolução do mercado de bioetanol no Brasil e nos EUA mostra a necessidade de uma aposta em outras rotas tecnológicas orientadas para aumento de produção com maior produtividade e sustentabilidade ambiental. Todavia, nesse quesito o Brasil vem se posicionando atrás dos EUA, onde os avanços tecnológicos e a alocação de recursos para pesquisa, desenvolvimento e inovação têm sido mais significativos, dado que o rol de instrumentos e ações do governo federal americano é a maior prova disso.

O objetivo desse trabalho é identificar o cenário tecnológico da produção de bioetanol do milho de primeira geração, a partir de um estudo de prospecção tecnológica junto às bases de dados de documentos de patentes sobre esse tema que foram depositados nos principais escritórios de proteção industrial do mundo. Este levantamento permitirá identificar o desenvolvimento tecnológico na área de estudo ao longo dos anos; as principais áreas científicas e tecnológicas estudadas por esses depositantes; e os principais países que receberam o primeiro depósito das patentes (país prioridade).

\section{Referencial Teórico}

O bioetanol é um álcool composto por um único tipo de molécula e é utilizado como combustível considerado ecologicamente correto, pois o cultivo de sua matériaprima reduz a quantidade de gás carbônico na atmosfera por meio da fotossíntese. Esse combustível pode ser produzido a partir de matérias-primas que contenham amido ou açúcares.

Segundo Macedo (1993), diversas matérias-primas podem ser utilizadas para a produção de etanol, e podem ser divididas em três categorias. A primeira é o grupo de produtos chamados sacaríneos, assim conhecidos por possuírem o açúcar sacarose que dá origem ao etanol, como por exemplo, a cana-de-açúcar, sorgo sacarino (colmo), beterraba e sucos de frutas em geral. O segundo é o conjunto de produtos relacionados aos amiláceos, que possuem esse nome por conterem amido, destacam-se a mandioca, 
milho, cereais de um modo geral, sorgo (grãos), batata e babaçu (mesocarpo). A terceira categoria é a de matérias-primas celulósicas, na qual o etanol é produzido a partir da celulose existente em sua composição, na qual se destacam: eucalipto, marmeleiro, serragem, bagaço de cana, pericarpo de babaçu, casca de arroz, entre outros.

A cana-de-açúcar é a matéria-prima mais utilizada mais utilizada para a produção de etanol e açúcar, sua produção agrícola e processamento industrial concentra-se basicamente em países da América Latina, África do Sul, Índia e na Austrália. Nos EUA e no Canadá o milho é o produto predominante para a produção de etanol e a beterraba açucareira para a produção de açúcar. Na Europa a beterraba é utilizada para a produção de açúcar (França, Alemanha, Espanha e Itália) e matériasprimas celulósicas na produção de etanol, na Suécia utilizam-se restos florestais. A mandioca, trigo e sorgo são mais utilizados nos países asiáticos para a produção de etanol.

De maneira geral, o etanol produzido a partir da extração direta do caldo dos sacaríneos e dos amiláceos é denominado de etanol de primeira geração, trata-se do método mais tradicional e historicamente difundido entre aos principais produtores de etanol e açúcar do mundo. A tecnologia de produção de etanol de primeira geração tem sido desenvolvida e difundida inicialmente para a produção de bebidas, e posteriormente, por volta de um século, para a produção de etanol combustível.

A produção de etanol a partir de grupos de produtos celulósicos, o chamado etanol de segunda geração, vem sendo estudado mais recentemente e apresenta algumas rotas tecnológicas de produção ainda em desenvolvimento. Trata-se de um método que permite o aproveitamento integral da matéria-prima processada em duas fases: i) na primeira extraindo o caldo dos sacaríneos ou dos amiláceos e processando tradicionalmente para a produção de etanol; ii) em uma segunda etapa, a celulose, subproduto da primeira fase independente do tipo de matéria-prima utilizada, é processada em reatores enzimáticos e extraído o etanol de segunda geração.

Segundo Jardine et al. (2009), as matérias-primas amiláceas necessitam da conversão do amido em açúcares por um processo enzimático a altas temperaturas. No caso das matérias-primas açucareiras, como a cana-de-açúcar e a beterraba, os açúcares já estão disponíveis na biomassa, sendo necessária apenas a extração destes para a produção do biocombustível.

O bioetanol pode ser obtido a partir de qualquer biomassa que contenha quantidades significativas de carboidratos, particularmente amido ou açúcares. De maneira geral, a Figura 1 apresenta esquematicamente as rotas tecnológicas da produção de bioetanol em função dos diferentes grupos de matérias-primas conhecidas. No caso da produção a partir de sacaríneos o processo é mais simples, envolvendo menos operações unitárias, uma vez que os açúcares disponíveis na biomassa são diretamente fermentáveis, dispensando etapas de hidrólise, comum nas matérias-primas amiláceas. A produção de bioetanol utilizando produtos celulósicos (segunda geração) ainda encontra-se em pesquisas de desenvolvimento, com poucas plantas em operação e com rota tecnológica ainda por definir. 


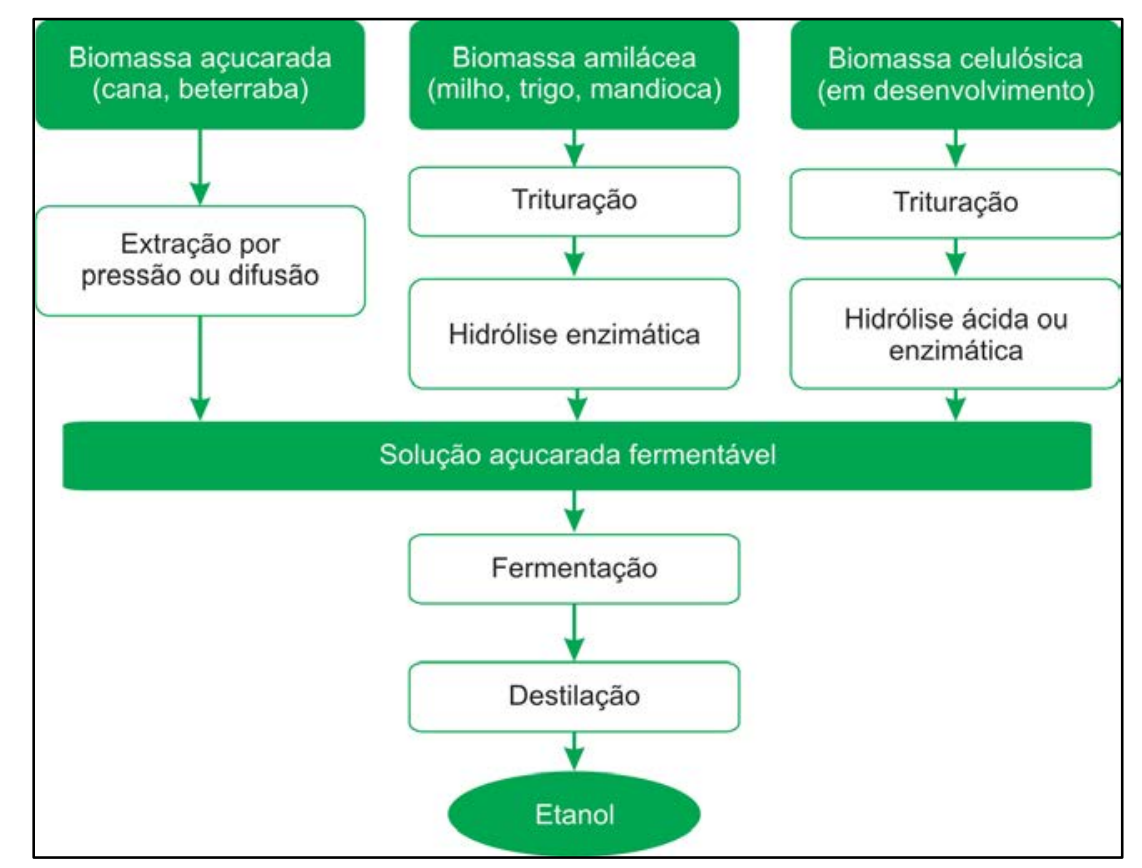

Figura 1 - Diferentes rotas tecnológicas para a produção de bioetanol Fonte: BNDES (2008)

O milho é uma planta da família das gramíneas originada do México e vem sendo cultivado em todos os continentes. Seu cultivo ocupa o equivalente a 147 milhões de hectares em todo o mundo e é considerado um componente alimentício de grande importância. Na sua matéria seca o milho é composto de $70 \%$ a $75 \%$ de amido; $10 \%$ de proteína; de $4 \%$ a $5 \%$ de gérmen; entre $3 \%$ e $4 \%$ de fibras e $2 \%$ de cinzas. O processo fotossintético do milho tem como produto final o amido, que constitui sua reserva de carbono. É este amido, que através da hidrólise, produzirá a sacarose que será fermentada para a produção de etanol (BNDES, 2008).

Segundo Novozymes (2002), a partir do milho pode-se produzir bioetanol por meio de dois processos: i) moagem úmida; ii) ou a seca. Até meados da década de 1990 a opção úmida era a mais utilizada, porém, atualmente a seca tem apresentado vantagens comparativas importantes, tanto no custo operacional, quando o rendimento do produto final, e passou a ser a mais utilizada. Na via úmida, o grão de milho é separado em frações, o que possibilita a recuperação de diversos produtos, como proteínas, nutrientes, amido e o óleo. Feito o fracionamento do grão, o amido é convertido em açúcares por um processo enzimático, os açúcares são fermentados com a ajuda de leveduras especiais e o mosto resultante é destilado e convertido em bioetanol (Figura 2). 


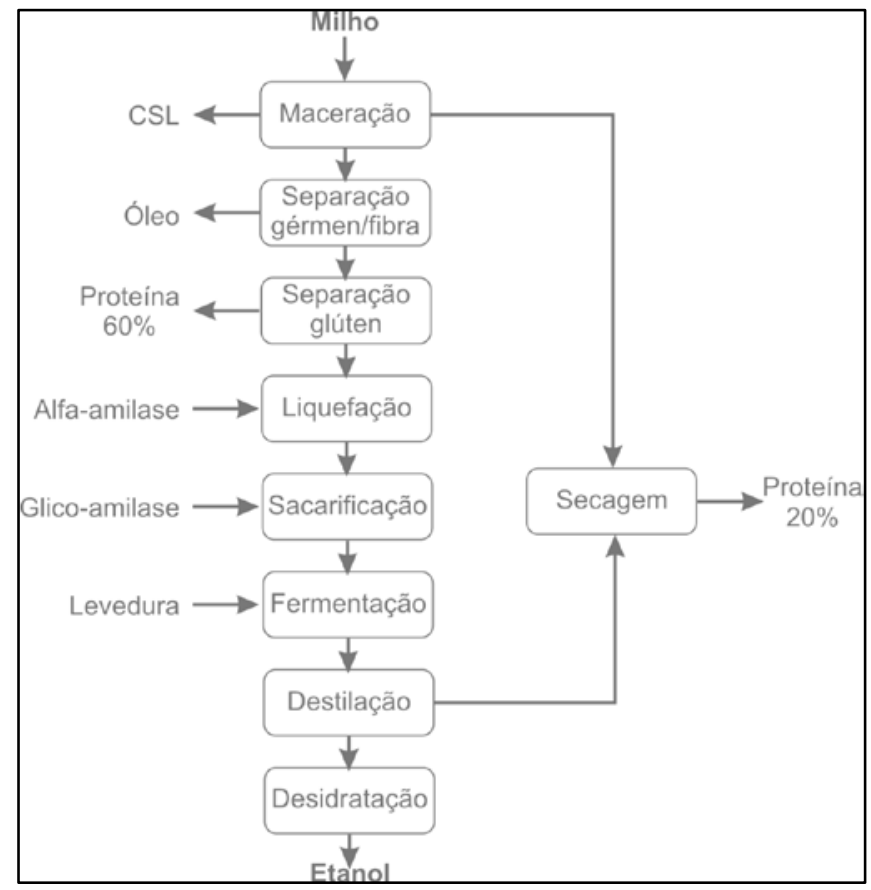

Figura 2 - Fluxograma geral do processo de obtenção de bioetanol de milho (via úmida)

Fonte: BNDES (2008).

Segundo Jardine et al. (2009), pela via úmida, cada tonelada de milho processada produz o equivalente a 440 litros de bioetanol e o óleo de milho. Pela via seca (Figura 3) o grão de milho moído é adicionado à água e enzimas para promover a hidrólise do amido em cadeias menores de açúcar, neste caso, o único co-produto do etanol é um suplemento proteico (DDGS - distillers dried grains with solubles) e o dióxido de carbono. O DDGS contém 26\% de proteína, $8 \%$ de gordura e 12\% de fibra, sendo utilizado como insumo para a fabricação de rações, e o dióxido de carbono comercializado com indústrias de refrigerantes e gelo seco. Neste caso o rendimento fica em torno de 460 litros de etanol e $380 \mathrm{~kg}$ de DDGS.

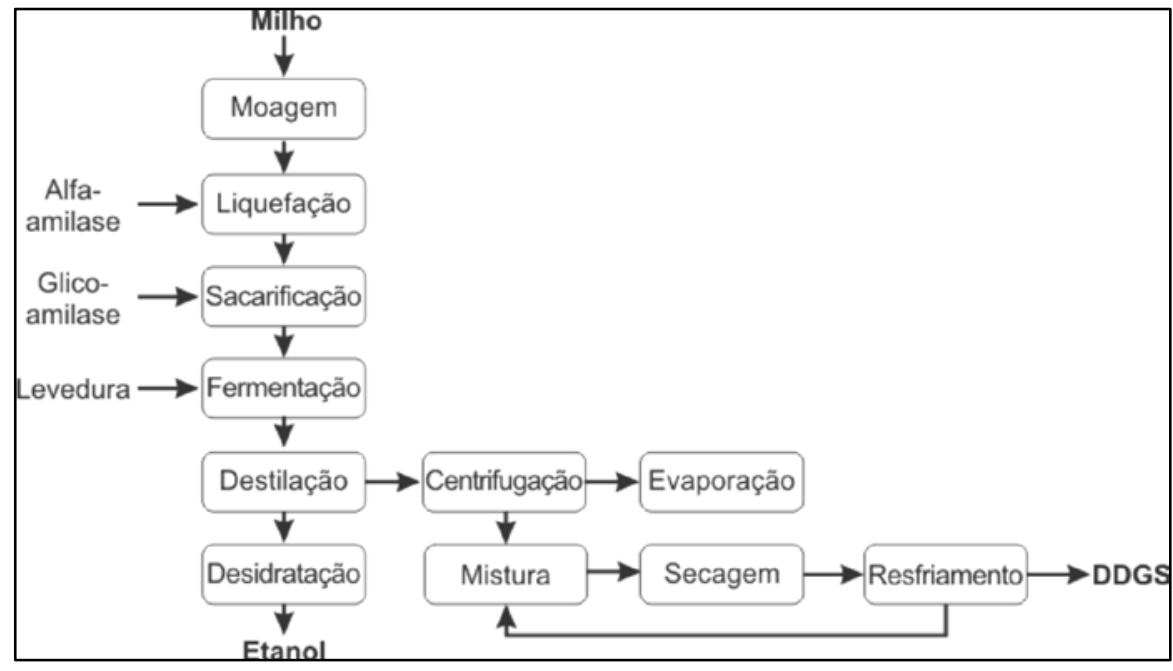

Figura 3 - Fluxograma geral do processo de obtenção de bioetanol de milho (via seca). Fonte: BNDES (2008). 
Independente da via, úmida ou seca, o processo de liberação de açúcares durante a produção de etanol de milho desenvolve-se rapidamente no início, mas tende a reduzir sua velocidade em pouco tempo. Trata-se da etapa de hidrólise do milho, a mais crítica do processo de fabricação e que pode durar até 72 horas, neste caso é comum realizar as etapas de sacarificação e fermentação de maneira simultânea a fim de diminuir o tempo de processo.

Depois de fermentado, o produto segue para as colunas de destilação do mesmo modo como ocorre com a cana-de-açúcar. Entretanto, a vinhaça, resíduo da destilação, segue para um conjunto de centrífugas onde é separada a vinhaça fina, que muitas vezes é recirculada no processo para o melhor aproveitamento dos açúcares. Após a destilação, o etanol passa pelo processo de desidratação, que é realizado mais comumente nos EUA por peneira molecular, enquanto no Brasil, para o etanol de cana, ainda é mais utilizada a adição de cicloexano.

Segundo o USDA (Departamento de Agricultura dos Estados Unidos) os EUA são os principais produtores de bioetanol do mundo. Na safra 2015/16 foram produzidos naquele país o equivalente a 54 bilhões de litros de etanol de milho, dos quais 51 bilhões foram consumidor internamente e aproximadamente 3 bilhões de litros exportados, inclusive para o Brasil (USDA, 2015). No Brasil, segundo a UNICA (União dos Canavieiros Paulistas), na safra de 2015/16 foi produzido o equivalente a 30 bilhões de litros de etanol total (anidro e hidratado) a partir da cana-de-açúcar e importado aproximadamente 429 milhões de litros, sendo 116 milhões dos EUA.

O real impulso à demanda por etanol nos EUA ocorreu no final da década de 1990, quando foi instituído o Clean Air Act, uma lei que estabeleceu um conjunto de padrões da qualidade do ar das áreas americanas (usualmente referidas às cidades de maior tamanho). A fim de cumprir o estabelecido na carta legal da década de 1990 o senado americano instituiu a partir de 2003 a chamada The Energy Policy Act, dentre as medidas discutidas incluiu-se um cronograma de implantação do programa de combustíveis renováveis nos EUA, destacando toda a forma de biocombustíveis como, por exemplo, o biodiesel e o etanol. A atual política de energia prevê subvenções do governo às indústrias, na forma de créditos tributários e foi a principal responsável pela viabilização do crescimento da indústria de etanol de milho dos EUA (FIGUEIRA, 2005).

\section{Metodologia}

A metodologia adotada para a construção do artigo teve como base o mapeamento de informações relevantes com a finalidade de identificar os documentos de patentes relacionados com a tecnologia de produção de bioetanol a partir do milho depositada nos principais escritórios de proteção industrial do mundo, entre os anos de 1975 e 2015. Para tanto foi utilizado a ferramenta de prospecção tecnológica Questel Orbit. Trata-se de um sistema de busca e análise de informações contidas em patentes e desenhos industriais, cujo diferencial está no agrupamento por família de patentes, buscas por status de tramitação, facilidade de visualização e exportação de resultados. $\mathrm{O}$ sistema traz ferramentas de análise estatística e correlacional, as quais permitem a geração e visualização de gráficos sobre grandes conjuntos de patentes.

O sistema permite busca por meio de palavras-chaves, campos bibliográficos, classificação de patentes, citações, famílias de patentes e status legal. A cobertura da base Questel Orbit abrange mais de 96 países para patentes, sendo 21 deles com textos integrais pesquisáveis e arquivos disponíveis para download. 
Os termos de busca utilizados foram baseados em definir palavras-chaves para cada setor do campo tecnológico e nos códigos da Classificação Internacional de Patentes (IPC) para cada etapa do processo, conforme utilizado por Lima et al. (2013). O objetivo foi fazer uma varredura nos documentos de patentes encontrados e identificar por meio da Classificação Internacional de Patentes (CIPs) os que efetivamente estão relacionados com áreas de conhecimentos ligadas a produção de bioetanol a partir do milho. A estratégia de busca utilizada para cada etapa da produção de etanol a partir do milho pode ser observada no Quadro 1.

Assim, pode-se obter, entre outras informações: i) número de patentes separando-as por subdomínio tecnológico; ii) número de patentes por país de origem do titular; iii) número de outros depósitos das patentes separando-as pelo país do outro depósito; iv) número de patentes por titular.

Quadro 01 - Detalhamento das Estratégias Empregadas nas Buscas (Campo Temporal: 1975-2015)

\begin{tabular}{|c|c|c|}
\hline $\begin{array}{l}\text { Campo } \\
\text { Tecnológico }\end{array}$ & Palavras-Chave & Códigos CIP \\
\hline $\begin{array}{l}\text { Processos/Métodos } \\
\text { (Geral) }\end{array}$ & $\begin{array}{l}\text { corn and (fuel or biofuel or bioethnol or } \\
\text { ethanol or bioconvers) }\end{array}$ & \\
\hline Corte/Picotamento/Fatiamento & $\begin{array}{l}\text { corn and (fuel or biofuel or bioethnol or } \\
\text { ethanol or bioconvers) }\end{array}$ & $\begin{array}{l}\text { AND (A01f* or } \\
\text { C13b*) }\end{array}$ \\
\hline Moagem & $\begin{array}{l}\text { corn and (crush or comunnit or mill or } \\
\text { grind) }\end{array}$ & $\begin{array}{l}\text { AND }\left(\mathrm{C} 13^{*} \text { or }\right. \\
\text { B30B* or B02C*) }\end{array}$ \\
\hline $\begin{array}{l}\text { Fermentação de } \\
1^{\text {a }} \text { Geração }\end{array}$ & $\begin{array}{l}\text { corn and (extract or juice) and (ferment* or } \\
\text { zymos* or Saccharom* or enzym* or } \\
\text { hydrol* or yeast*) }\end{array}$ & $\begin{array}{l}\text { NOT }\left(\mathrm{A} 01^{*} \text { or }\right. \\
\mathrm{A} 21^{*} \text { or } \mathrm{A} 61^{*} \text { or } \\
\mathrm{A} 23^{*} \text { or } \mathrm{C} 12 \mathrm{C}^{*} \\
\text { or } \mathrm{C} 12 \mathrm{G}^{*} \text { or } \\
\left.\mathrm{C} 12 \mathrm{~J}^{*}\right)\end{array}$ \\
\hline $\begin{array}{l}\text { Fermentação de } \\
2^{\text {a }} \text { Geração }\end{array}$ & $\begin{array}{l}\text { corn and (Biomass or Bagasse or Fibr* or } \\
\text { Leaf or Straw or Lign* or Celull* or } \\
\text { Hemicell* or Xyllose) and (Fermnt* or } \\
\text { enzym* or hydrol*) }\end{array}$ & $\begin{array}{l}\text { NOT }\left(\mathrm{A} 01^{*} \text { or }\right. \\
\mathrm{A}^{*} 1^{*} \text { or } \mathrm{A} 61^{*} \text { or } \\
\mathrm{A}^{*} 3^{*} \text { or } \mathrm{C} 12 \mathrm{C}^{*} \\
\text { or } \mathrm{C} 12 \mathrm{G}^{*} \text { or } \\
\left.\mathrm{C} 12 \mathrm{~J}^{*}\right)\end{array}$ \\
\hline
\end{tabular}

Fonte: Elaborado pelos autores

O Quadro 2 apresenta a descrição dos códigos das classificações internacionais de patentes utilizadas na estratégia de busca. Destaca-se que estas foram utilizadas com o objetivo de obter um resultado satisfatório na busca de patentes. Para a busca de patentes do processo como um todo não foram utilizadas as CIPs. No caso das etapas de corte, picotamento e fatiamento foram usadas classificações relacionadas ao processo. Para as etapas de fermentação de $1^{\mathrm{a}}$ e $2^{\mathrm{a}}$ geração foram utilizadas classificações não relacionadas ao tema de interesse desse trabalho, porém utilizou-se o termo NOT para que as patentes que estivessem nessas classificações não fossem consideradas no resultado da busca. 
Quadro 02 - Descrição dos códigos de CIPs utilizadas nas estratégias de buscas

\begin{tabular}{|c|c|c|}
\hline $\begin{array}{c}\text { Campo } \\
\text { Tecnológico } \\
\end{array}$ & Códigos CIP & Descrição da Tecnologia \\
\hline \multirow{2}{*}{ Corte/Picotamento/Fatiamento } & $\mathrm{A} 01 \mathrm{~F}$ & Processamento do produto colhido \\
\hline & C13B & $\begin{array}{l}\text { Produção } \\
\text { especialmente }\end{array}$ \\
\hline \multirow{3}{*}{ Moagem } & C13 & Indústria do Açucar \\
\hline & В30B & $\begin{array}{l}\text { Prensas em geral; Prensas não incluídas em } \\
\text { outro local }\end{array}$ \\
\hline & B02C & $\begin{array}{l}\text { Trituração, pulverização ou desintegração em } \\
\text { geral; moagem do grão }\end{array}$ \\
\hline \multirow{7}{*}{$\begin{array}{l}\text { Fermentação de } \\
1^{\text {a }} \text { e } 2^{\text {a }} \text { Geração }\end{array}$} & A01 & $\begin{array}{l}\text { Agricultura; silvicultura; pecuária; caça; } \\
\text { captura em armadilhas; pesca }\end{array}$ \\
\hline & A21 & $\begin{array}{l}\text { Cozedura ao forno; equipamento para preparo } \\
\text { ou processamento de massas; massas para } \\
\text { cozedura ao forno }\end{array}$ \\
\hline & A61 & Ciência Médica ou veterinária; higiene \\
\hline & A23 & Alimentos ou produtos alimentícios \\
\hline & $\mathrm{C} 12 \mathrm{C}$ & Produção de cerveja \\
\hline & C12G & $\begin{array}{l}\text { Vinho; outras bebidas alcoólicas; sua } \\
\text { preparação }\end{array}$ \\
\hline & C12J & Vinagre; sua preparação \\
\hline
\end{tabular}

Fonte: Elaborado pelos autores

\section{Resultados}

A pesquisa realizada no software Questel Orbit com os termos previamente selecionados com foco nos processos e métodos para a produção de bioetanol de milho, ou seja, considerando o processo com um todo, resultaram em 1.246 documentos (Gráfico 1). No período compreendido entre 2007 e 2015 foram depositados 872 documentos, o que representa aproximadamente $70 \%$ do total de documentos pesquisados (aproximadamente 40 anos). 
Gráfico 1 - Distribuição dos resultados obtidos com os termos de busca geral por ano (de acordo com a data de depósito)

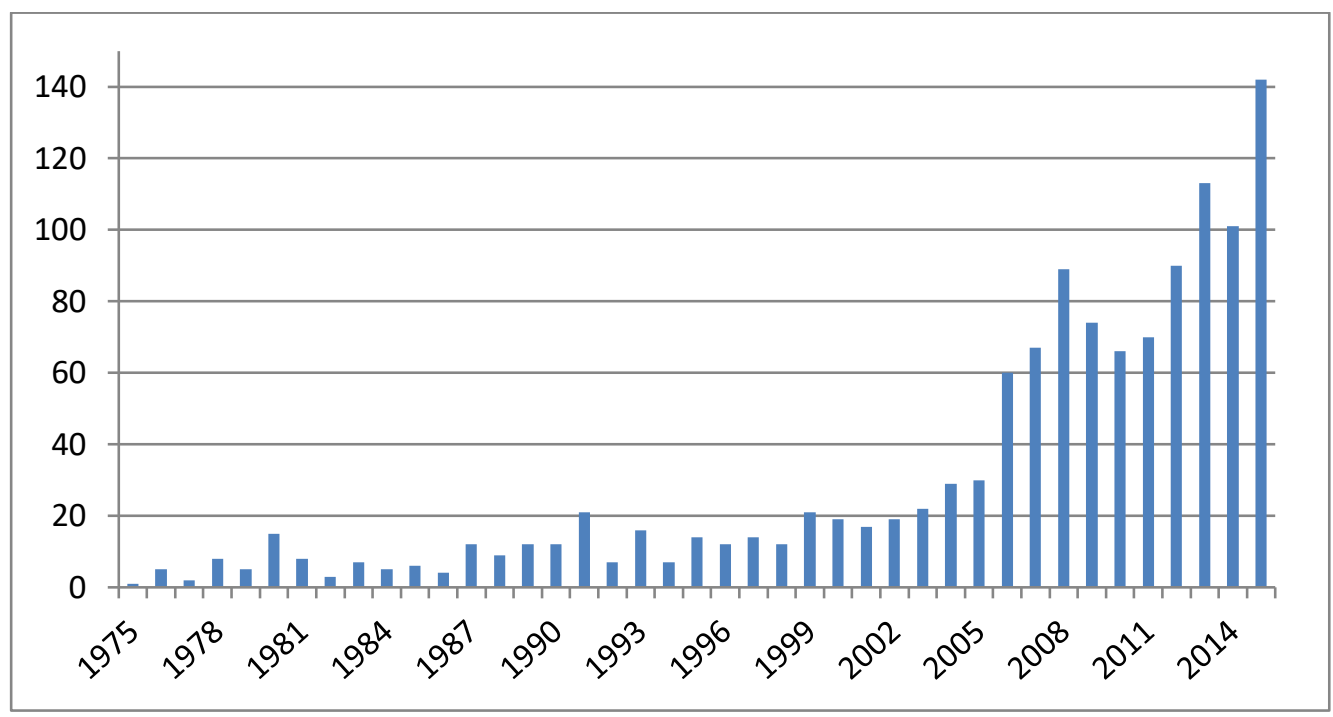

Fonte: Dados obtidos pelos autores a partir de pesquisa com termos de busca no QuestOrbit.

Em relação aos termos de busca associados aos processos de corte, picotamento e fatiamento observa-se que foram encontrados 30 documentos e que a maioria dos depósitos foram realizados a partir de 2007 (Gráfico 2).

Gráfico 2 - Distribuição dos resultados obtidos com os termos de busca selecionados para os processos de corte, picotamento e fatiamento por ano (de acordo com a data de depósito)

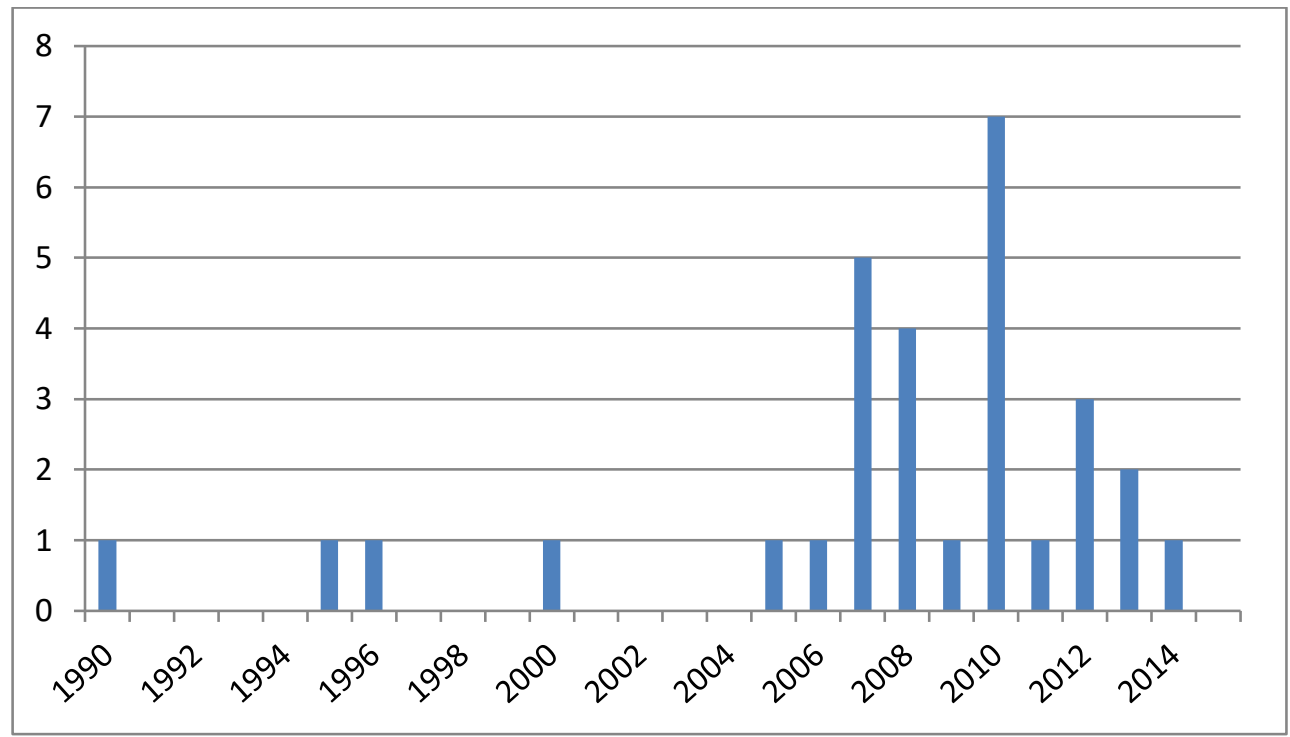

Fonte: Dados obtidos pelos autores a partir de pesquisa com termos de busca no QuestOrbit. 
Para a etapa de moagem foram encontrados 374 documentos durante o período analisado. Nessa fase da busca observa-se que houve, em média, 9 depósitos por ano (Gráfico 3).

Gráfico 3 - Distribuição dos resultados obtidos com os termos de busca selecionados para moagem por ano (de acordo com a data de depósito)

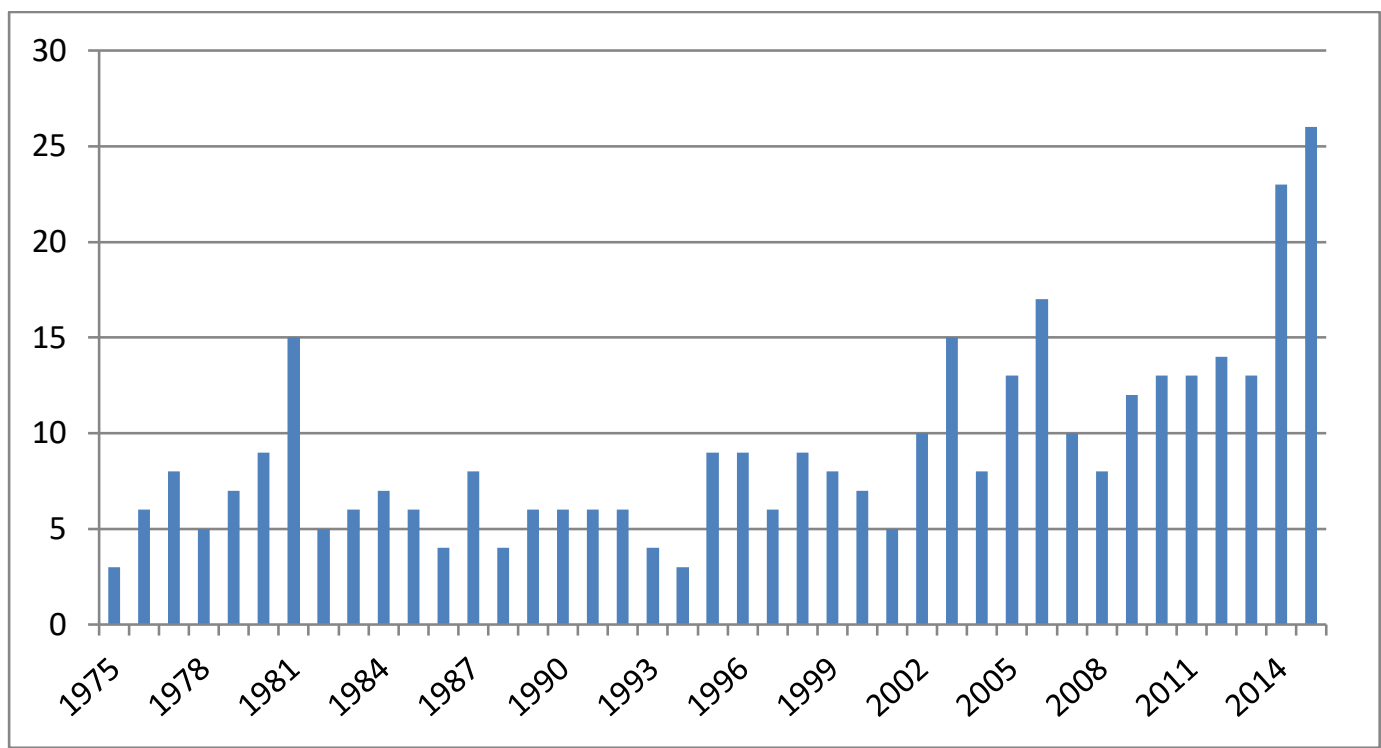

Fonte: Dados obtidos pelos autores a partir de pesquisa com termos de busca no QuestOrbit.

Para o processo de fermentação de $1^{\text {a }}$ geração observou-se o depósito de 20 documentos. Nota-se que o primeiro depósito ocorreu em 1995 e o próximo somente em 2002, o que configura-se um processo tecnológico mais recente e menos explorada do que os anteriores (Gráfico 4).

Gráfico 4 - Distribuição dos resultados obtidos com os termos de busca selecionados para fermentação de $1^{\mathrm{a}}$ geração por ano (de acordo com a data de depósito)

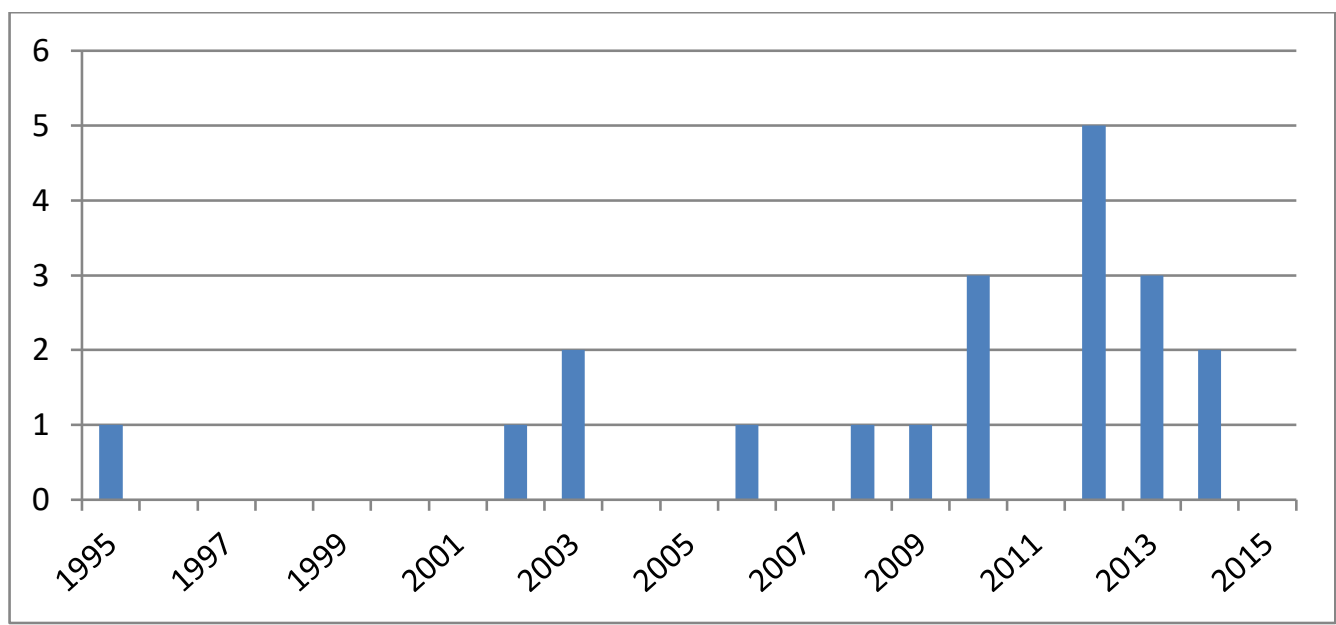

Fonte: Dados obtidos pelos autores a partir de pesquisa com termos de busca no QuestOrbit. 
No processo de fermentação de $2^{\mathrm{a}}$ geração foram encontrados 46 documentos, sendo o primeiro datado de 1985. Observa-se que a partir de 2006 uma continuidade em relação aos depósitos de patentes (Gráfico 5).

Gráfico 5 - Distribuição dos resultados obtidos com os termos de busca selecionados para fermentação de $2^{a}$ geração por ano (de acordo com a data de depósito)

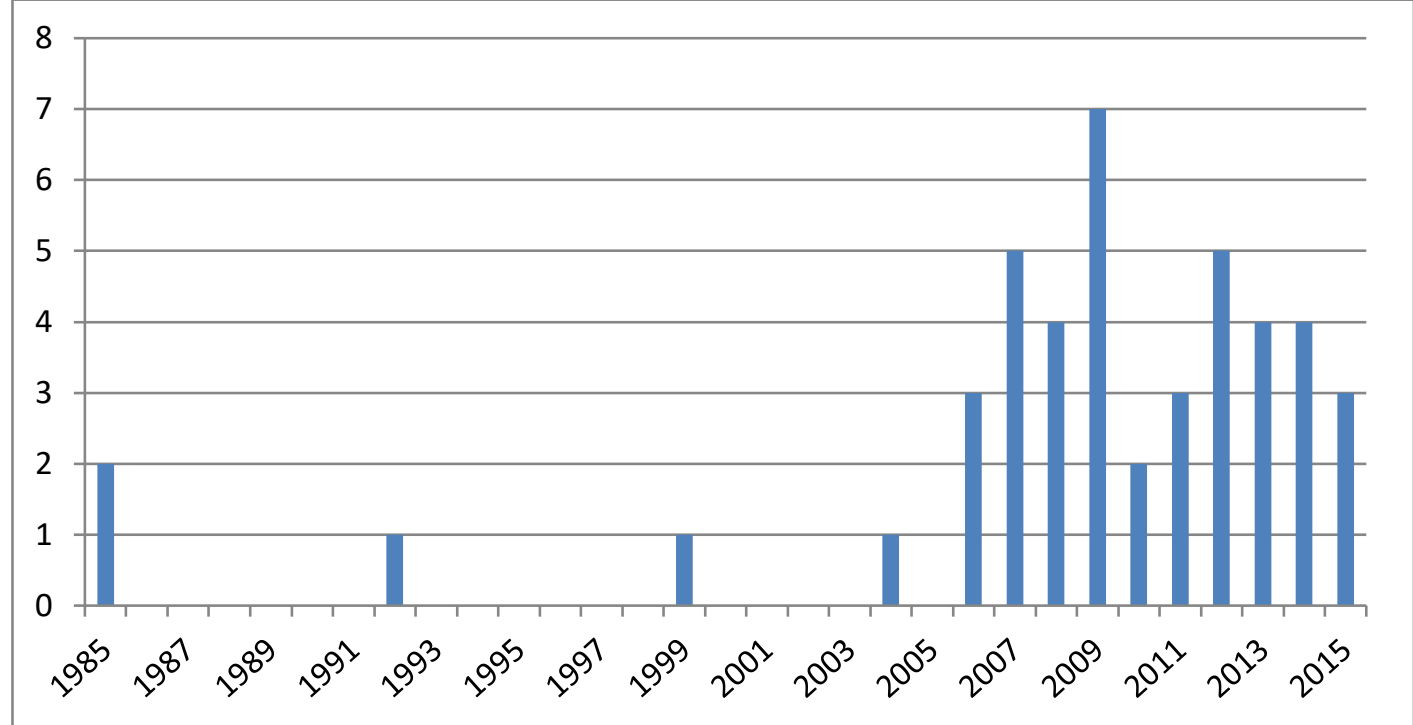

Fonte: Dados obtidos pelos autores a partir de pesquisa com termos de busca no QuestOrbit.

O Gráfico 6 apresenta a distribuição dos documentos de patentes observados durante a pesquisa de acordo com seu país de origem. Dentre os documentos encontrados para o termo de busca geral, 49,2\% dos documentos foram depositados na China (CN), 19,4\% nos Estados Unidos (US), 10,2\% no Japão (JP), 2,5\% na Rússia (RU), 0,9\% na França (FR), 0,8\% no Brasil (BR), entre outros menos expressivos. Verifica-se que 7 documentos (0,6\%) foram depositados com a sigla WO, que refere-se aos pedidos PCT (Patent Cooperation Treaty), que são aqueles que apresentam depósito em mais de um país ao mesmo tempo. Cabe ressaltar que a distribuição das nacionalidades dos depositantes não é capaz de identificar em quais países há maior desenvolvimento de pesquisas com o tema em estudo, pois muitas firmas que atuam neste mercado têm centros de pesquisa em países distintos. 
Gráfico 6 - Distribuição dos resultados obtidos com o termo de busca para todo o processo por país em que a invenção foi depositada inicialmente - país prioridade - no período de 1975 a 2015.

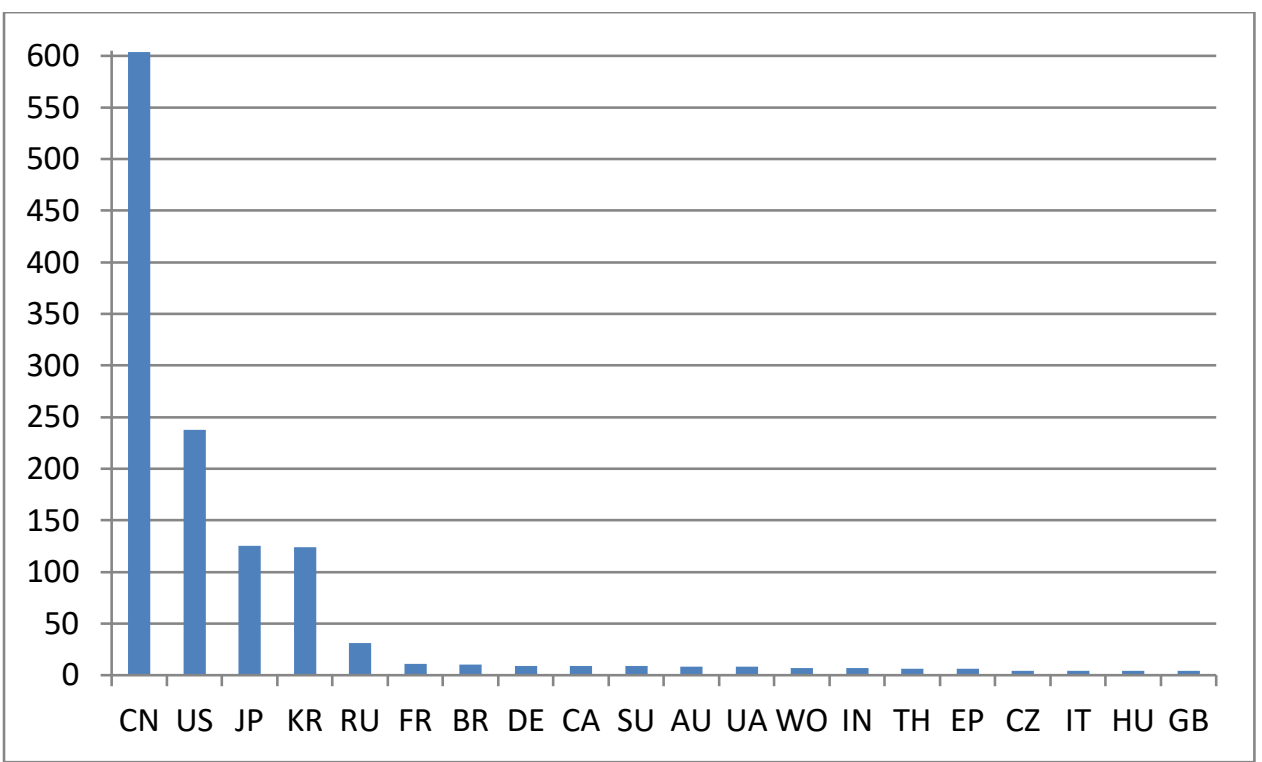

Fonte: Dados obtidos pelos autores a partir de pesquisa com termos de busca no QuestOrbit.

Em relação aos termos de busca associados aos processos de corte, picotamento e fatiamento observa-se que 50\% dos documentos foram depositados na China (CN), 20\% nos Estados Unidos (US), 6,7\% na Austrália (AU) e Alemanha (DE), entre outros menos significativos (Gráfico 7).

Gráfico 7 - Distribuição dos resultados obtidos com o termo de busca para os processos de corte, picotaento e fatiamento por país em que a invenção foi depositada inicialmente - país prioridade - no período de 1975 a 2015.

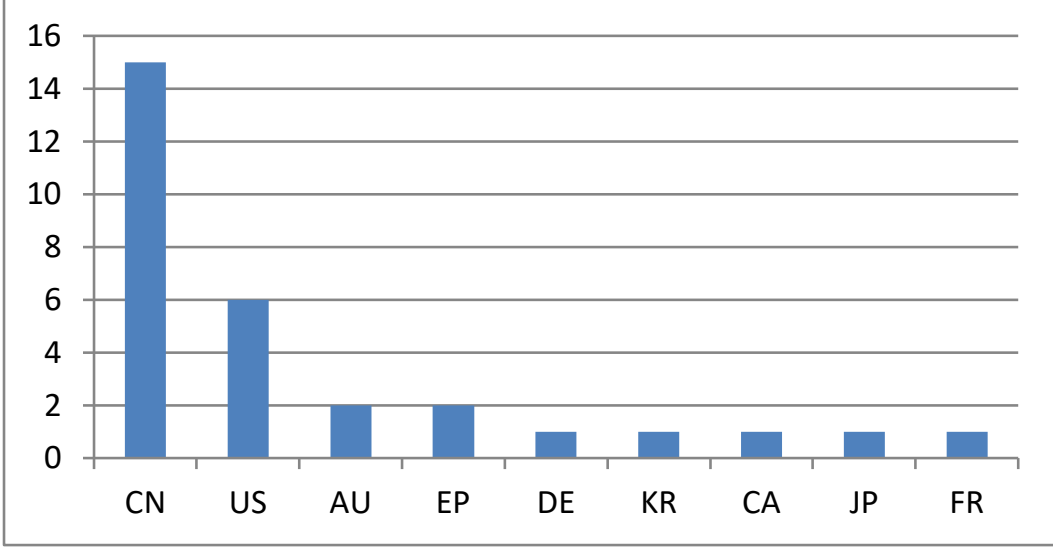

Fonte: Dados obtidos pelos autores a partir de pesquisa com termos de busca no QuestOrbit.

Para a etapa de moagem 38,7\% dos documentos foram depositados na China (CN), 18,2\% nos Estados Unidos (US), 12\% na Alemanha (DE), aproximadamente 6\% 
no Japão (JP) e Coréia do Sul (KR), entre outros. Observa-se que 2 documentos foram depositados no Brasil (BR) como país prioridade (Gráfico 8).

Gráfico 8- Distribuição dos resultados obtidos com o termo de busca para a etapa de moagem por país em que a invenção foi depositada inicialmente - país prioridade - no período de 1975 a 2015.

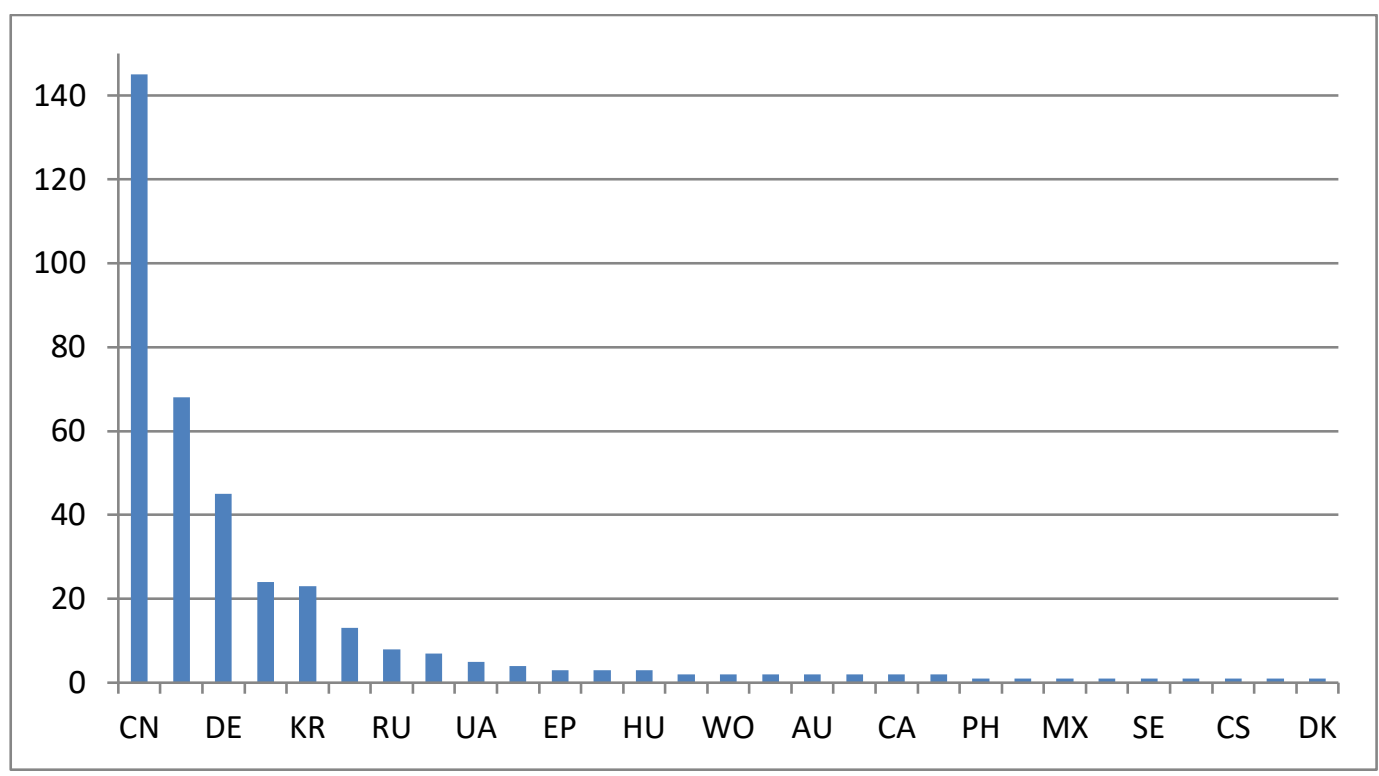

Fonte: Dados obtidos pelos autores a partir de pesquisa com termos de busca no QuestOrbit.

Para o processo de fermentação de $1^{\text {a }}$ geração observou-se que mais de $53 \%$ dos documentos foram depositados inicialmente na China (CN), 10\% na Coréia do Sul (KR) e 3,3\% na Índia (IN) (Gráfico 9).

Gráfico 9 - Distribuição dos resultados obtidos com o termo de busca para fermentação de $1^{\text {a }}$ geração por país em que a invenção foi depositada inicialmente - país prioridade no período de 1975 a 2015.

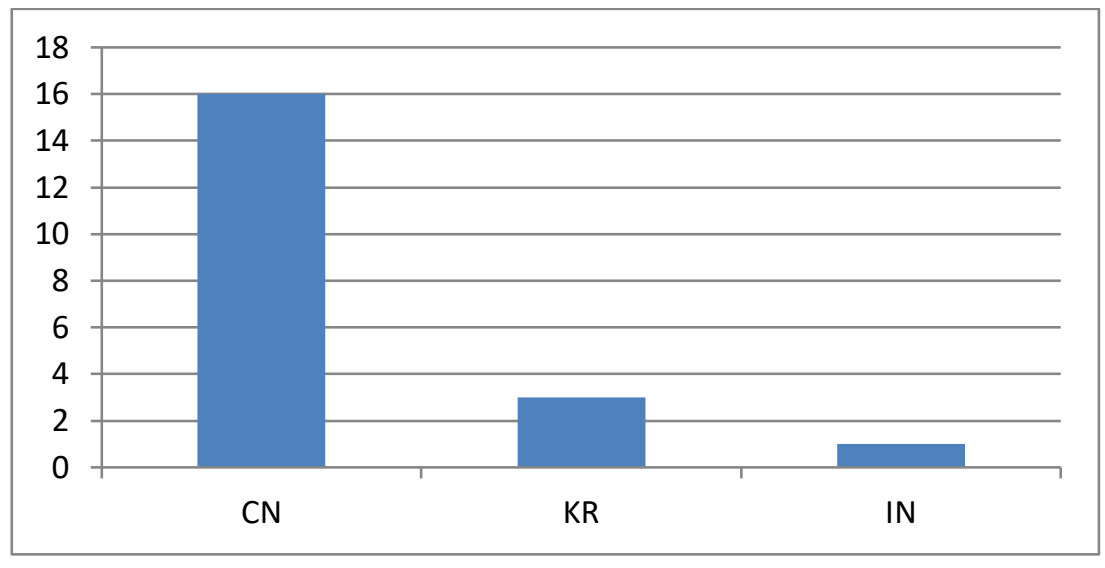

Fonte: Dados obtidos pelos autores a partir de pesquisa com termos de busca no QuestOrbit. 
No processo de fermentação de $2^{\mathrm{a}}$ geração os documentos foram depositados inicialmente (país prioridade) na China (78,3\%), Estados Unidos (10,9\%), Coréia do Sul (6,5\%). Foram encontrado, ainda, 1 documento depositado na Alemanha e com a sigla WO (Gráfico 10).

Gráfico 10 - Distribuição dos resultados obtidos com o termo de busca para fermentação de $2^{a}$ geração por país em que a invenção foi depositada inicialmente - país prioridade - no período de 1975 a 2015.

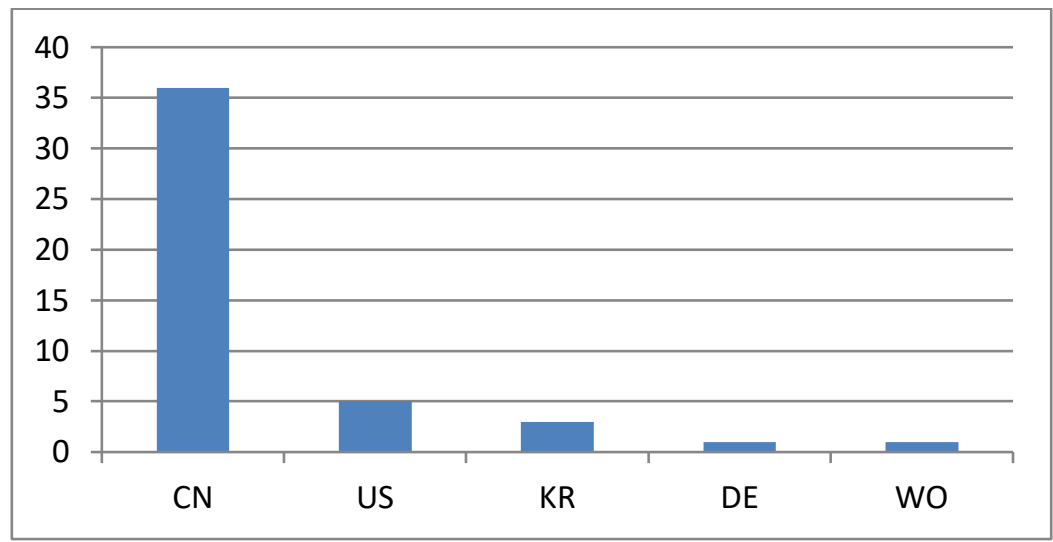

Fonte: Dados obtidos pelos autores a partir de pesquisa com termos de busca no QuestOrbit.

\section{Considerações Finais}

A pesquisa desenvolvida nesse trabalho permitiu verificar, a partir da busca dos termos selecionados com o software Questel-Orbit, a relevância da pesquisa envolvendo os processos para a produção de bioetanol a partir do milho nas principais bases de proteção industrial do mundo. Estudos desde tipo configuram uma importante ferramenta para o diagnóstico do estado da arte de determinadas tecnologias, para visualização dos principais detentores das técnicas e inovações vanguardistas e configuram um importante meio para ajudar na determinação de políticas de ciência e tecnologia em várias esferas de governo.

O levantamento dos documentos de patente estudados permitiu apontar aspectos importantes sobre as iniciativas de pesquisa e desenvolvimento na área em questão e ficou nítido que a China, Estados Unidos, Coréia do Sul, Índia e Japão destacam-se como país prioridade no depósito das patentes para as etapas estudadas. O Brasil aparece somente em 10 documentos como país prioridade na busca do processo como um todo e em 2 documentos no processo de moagem.

Para a obtenção do etanol a partir do milho o processo de fermentação de $1^{\mathrm{a}}$ geração é muito mais importante do que o de $2^{\mathrm{a}}$ geração. Apesar disso o número de patentes relacionadas à fermentação de $1^{\text {a }}$ geração (20 documentos) foi inferior aos encontrados para a fermentação de $2^{a}$ geração (46 documentos). Esse faro pode estar relacionado ao fato da tecnologia de produção de etanol de primeira geração ter sido desenvolvida e difundida inicialmente para a produção de bebidas, e posteriormente, para a produção de etanol combustível.

As pesquisas da produção de bioetanol a partir da fermentação de $2^{\mathrm{a}}$ geração ainda encontram-se em desenvolvimento, o que justifica o fato dos documentos de patentes para esse finalidade serem mais frequentes a partir de 2006. 


\section{Referencial Bibliográfico}

BNDES - BANCO NACIONAL DE DESENVOLVIMENTO ECONÔMICO E SOCIAL. Bioetanol de canade- açúcar: energia para o desenvolvimento Sustentável. Rio de Janeiro : BNDES; CGEE, 2008. 316 p.

FIGUEIRA, S. R. Programas para Álcool Combustível nos Estados Unidos e Possibilidades de Exportação do Brasil. Tese de Doutorado. Escola Superior de Agricultura Luiz de Queiroz - ESALQ/USP. Piracicaba, 2005.

JARDINE, J. G.; PERES, M. R.; DISPATO I. (2009). Indicações de aspecto tecnológico sobre o bioetanol de matéria-prima amilácea. In. Documento 94. Campinas, SP :Embrapa Informática Agropecuária, 2009, 23 p.

MACEDO, L. C. H. de. Etanol etílico: da cachaça ao cereal. São Paulo: Ícone, 1993

NOVOZYMES (2002). Fuel ethanol production: technological and environmental improvements. Novozymes \& BBI International, 2002.

PEREIRA, W. S. (2015). A participação do Estado no fomento ao etanol como uma oportunidade estratégica de desenvolvimento econômico: as políticas federais de estímulo ao etanol no Brasil e nos EUA. Tese (Doutorado) - Universidade Federal do Paraná, Setor de Ciências de Ciências Sociais Aplicadas, Curso de PósGraduação em Políticas Públicas, Curitiba, 2015.

SOUZA , A. P. et al.(2013). Sugarcane as a bioenergy source: history, performance, and perspectives for second-generation bioethanol. BioEnergy Research, v. online, p. online, 2013.

USDA (2015). World Agricultural Supply and Demand Estimates and National Agricultural Statistics Service. U.S. Bioenergy Statistics 2015. acessado: http://www.eia.gov/dnav/pet/pet_sum_snd_d_nus_mbbl_m_cur.htm; Bureau of Census, export data for Harmonized Tariff codes 2207106000 and 2207200000. 